\title{
Primary intracranial germ cell tumour originating from right brachium Pontis with hypertrophic Olivary degeneration: a case report
}

Yanong $\mathrm{Li}^{1+}$, Peng Wang ${ }^{1+}$, Jin Feng ${ }^{1}$, Jiayi Wang ${ }^{1}$, Jing Zhang ${ }^{1}$ and Xiaoguang Qiu $^{1,2^{*}}$ (D)

\begin{abstract}
Background: Primary right brachium pontis germinoma with hypertrophic olivary degeneration (HOD) is extremely rare. A preoperative diagnosis is challenging due to the absence of characterized clinical and neuroimaging features, and biopsy should be considered.

Case presentation: A 20-year-old male patient presented with a case of primary intracranial germinoma originating from right brachium pontis with HOD manifesting as ocular myoclonus, nystagmus in both eyes, ataxic gait and incoordination of the limbs. Magnetic resonance imaging (MRI) revealed an irregular patchy lesion with hyperintensity on T2-weighted images (T2WI) and T2 fluid-attenuated inversion recovery (FLAIR) without enhancement by gadolinium (Gd). Furthermore, a focal hyperintense nodule on T2WI in the left inferior olive nucleus (ION) of the medulla oblongata was considered hypertrophic olivary degeneration (HOD) based on the patient's symptoms and neuroimaging findings. Due to suspected demyelinating disease and low-grade glioma (LGG), a biopsy was planned. The pathological diagnosis was germinoma. Subsequently, he received chemoradiation therapy, resulting in the improvement of neurological deficits and the disappearance of the lesion on MRI.
\end{abstract}

Conclusion: A case of "Primary right brachium pontis germinoma with HOD" is reported for the first time. A preoperative diagnosis is challenging due to the fact of absence of clinical signs and symptoms and neuroimaging characteristics. However, patients can have favourable prognoses with appropriate evaluation and treatment.

Keywords: Germinoma, Hypertrophic olivary degeneration, Brachium pontis, Chemoradiation therapy

\footnotetext{
* Correspondence: qiuxiaoguang@bjtth.org

†Yanong Li and Peng Wang contributed equally to this work.

'Department of Radiation Oncology, Beijing Tiantan Hospital, Capital Medical

University, 119, South 4th Ring West Road, Fengtai District, Beijing, China

${ }^{2}$ Department of Molecular Neuropathology, Beijing Neurosurgery Institute,

Capital Medical University, Beijing, China
}

(c) The Author(s). 2021 Open Access This article is licensed under a Creative Commons Attribution 4.0 International License, which permits use, sharing, adaptation, distribution and reproduction in any medium or format, as long as you give appropriate credit to the original author(s) and the source, provide a link to the Creative Commons licence, and indicate if changes were made. The images or other third party material in this article are included in the article's Creative Commons licence, unless indicated otherwise in a credit line to the material. If material is not included in the article's Creative Commons licence and your intended use is not permitted by statutory regulation or exceeds the permitted use, you will need to obtain permission directly from the copyright holder. To view a copy of this licence, visit http://creativecommons.org/licenses/by/4.0/. The Creative Commons Public Domain Dedication waiver (http://creativecommons.org/publicdomain/zero/1.0/) applies to the data made available in this article, unless otherwise stated in a credit line to the data. 


\section{Background}

Central nervous system germ cell tumours (GCTs) represent a class of rare tumours with incidences ranging from 3.6\% in North America to $15.3 \%$ in some areas of Asia, and they commonly occur in children and adolescents [1]. Although intracranial GCTs are located mainly in the pineal and suprasellar regions, 5 to $10 \%$ of GCTs are located in the basal ganglia. Moreover, other atypical sites include the cerebellar vermis [2], ventricular system [3], and medulla oblongata [4]. Here, we describe a highly rare case of a primary central nervous system germinoma originating from right brachium pontis with hypertrophic olivary degeneration (HOD). To our knowledge, this is the first presented case of primary central nervous system germinoma of brachium pontis.

\section{Case presentation}

A 20-year-old male who had a resent history of 10month history of dizziness after strenuous activities, headache and vomiting and a 5-month history of progressive deterioration of fine movement of the right extremitiy. A neurological examination was performed; the patient's presented ocular myoclonus, nystagmus in both eyes, and ataxic gait, positive the finger-to-nose and heel-to-shin tests. Initial brain MRI, reviewed an irregular patchy $1.6-\mathrm{cm}$ isointense to hypointense lesion on T1-weighted image (T1WI) (Fig. 1a), no enhancement after contrast (Fig. 1c), and a hyperintense lesion on T2-weighted image (T2WI) (Fig. 1b) in the right brachium pontis involving ipsilateral cerebellar dentate nucleus was detected. The fourth ventricle appeared asymmetric on axial view. Additionally, a focal $0.7-\mathrm{cm}$ hyperintense nodule on T2WI in the left inferior olive nucleus (ION) of the medulla oblongata was considered hypertrophic olivary degeneration (HOD) according to the patient's symptoms and neuroimaging findings (Fig. 2a and b). With suspected demyelinating disease and low-grade glioma (LGG), a biopsy was arranged. Operatively, the lesion in the right brachium pontis was solid and grey-coloured, and the biopsy result was GCT. In contrast to the initial suspicious diagnosis, the pathological diagnosis of the main lesion in the right brachium

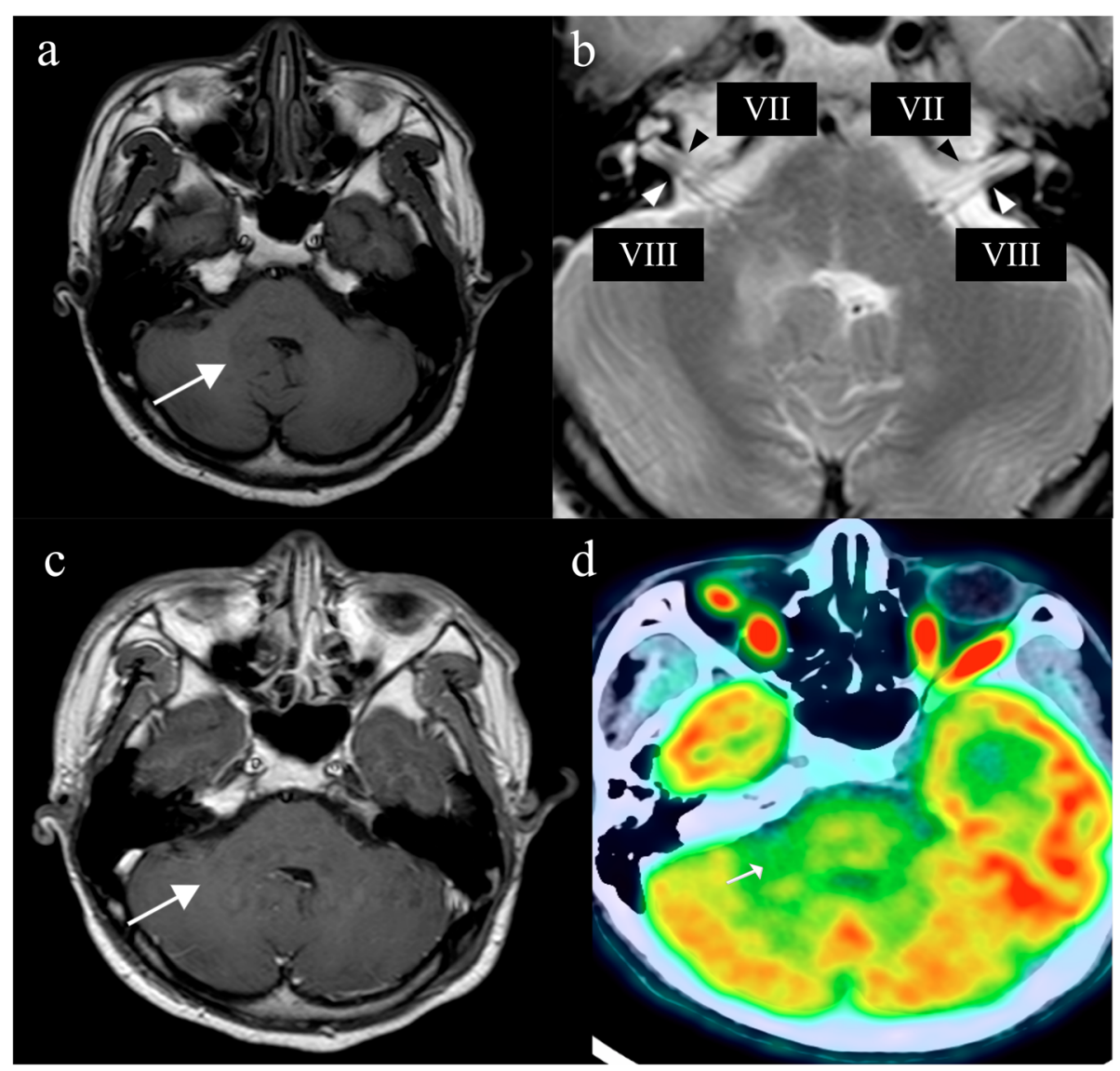

Fig. 1 Axial T1 (a), T2 (b), and T1-weighted contrast-enhanced (c) MR images demonstrate an expansile ill-defined patchy lesion involving the right side of the middle cerebellar peduncle and dentate nucleus (arrows) as well as the displacement of the fourth ventricle. However, the ipsilateral facial nerve (black arrowhead) and vestibulocochlear nerve (white arrowhead) were not affected. The fused PET image (d) of the ${ }^{18} \mathrm{~F}-\mathrm{FDG}$ PET/CT scan presents a decreasing metabolic lesion (SUVmax $=6.3$ ) in the right brachium pontis that involves the ipsilateral cerebellar dentate nucleus (arrows) 


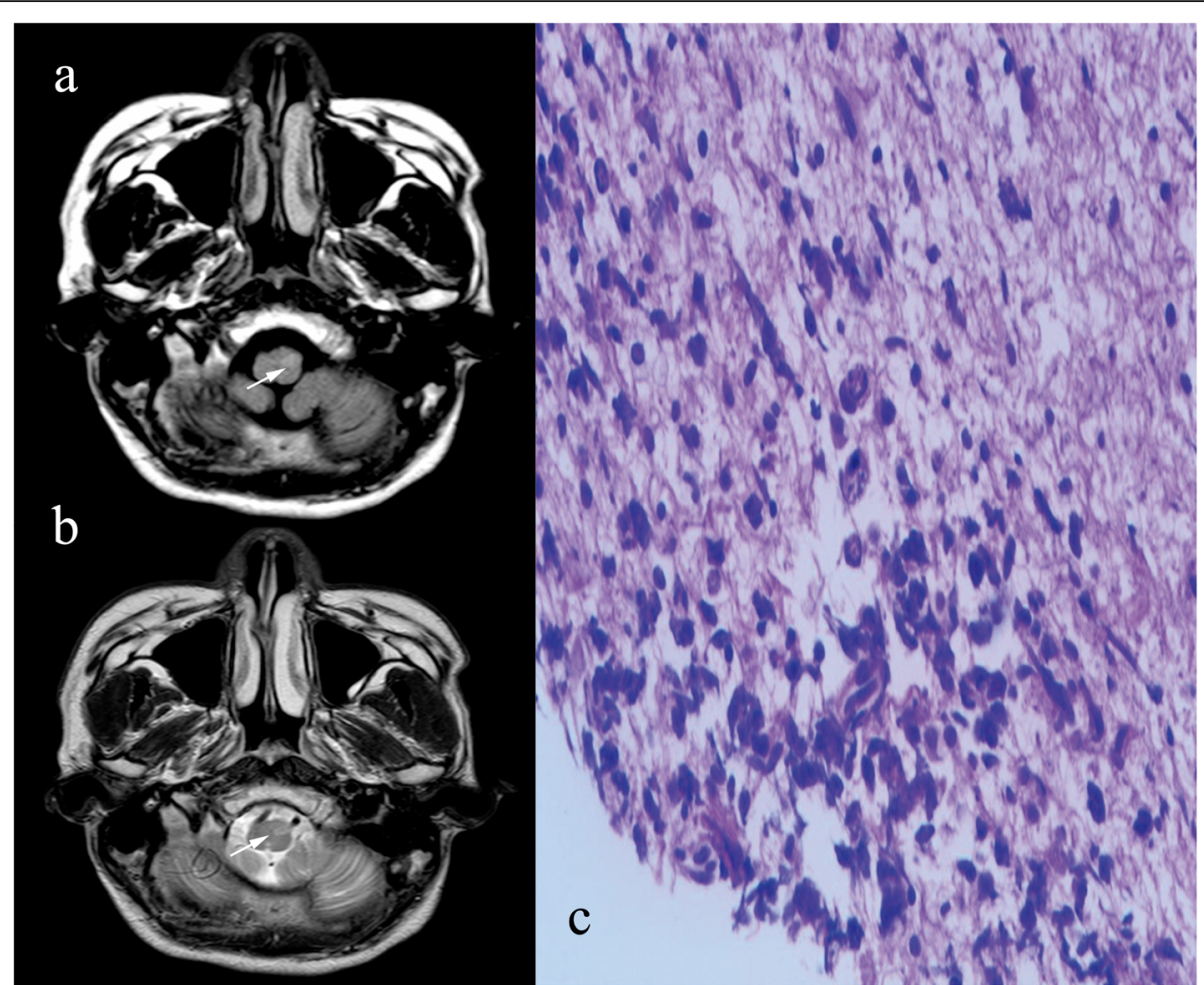

Fig. 2 Axial T2WI (a) and FLAIR (b) MR images reveal subtle hyperintensity in the contralateral inferior olive nucleus (arrows). Histopathological analysis $(\mathbf{c})$ reveals a cluster of pleomorphic cells with oval nuclei (immunohistochemistry, $\times 100$ )

pontis was germinoma. Focal expression of PLAP, OCT3/ 4 , and c-Kit was acquired, and alpha- fetoprotein (AFP), CD30 and placental alkaline phosphatase were not significant (Fig. 2c: immunohistochemistry, IHC; \& Fig. 3: Hematoxylin \& eosin stain, H\&E). Serum AFP (2.99 ng/ $\mathrm{mL})$ and $\beta$-hCG $(0.31 \mathrm{mU} / \mathrm{mL})$ levels were within the normal range. The brain ${ }^{18} \mathrm{~F}$-fluorodeoxyglucose positron emission tomography/computed tomography $\left({ }^{18} \mathrm{~F}\right.$-FDG $\mathrm{PET} / \mathrm{CT}$ ) examination found a hypodense lesion in the right brachium pontis showing slightly decreased metabolism with a maximum standardized uptake value (SUVmax) of 6.3 (Fig. 1d). After establishing the pathological diagnosis, the patient first received platinum-based chemotherapy followed by radiation therapy, including 23.4 Gy to the whole brain and 12.6 Gy to the tumour (total, 36 Gy), and then completed the remaining 4 cycles of chemotherapy based on the same regimen. Six months after chemoradiotherapy, the follow-up MRI (Fig. S1) showed no specific tumour residue and no evidence of dissemination, and the hyperintense nodule on T2W image in the left ION of the medulla oblongata had resolved. The patient is currently undergoing rehabilitation training, and the latest evaluation of muscle strength testing showed that the power of the right shoulder abductors and the elbow flexors was 4 , and the power of the elbow extensors and wrist extensors was $4+$. The power of hip flexors, knee extensors, dorsiflexion, great toe extensor, and plantar flexors was 4-. The last follow-up was 34 months after the end of treatment, and MRI revealed that the HOD had disappeared (Fig. S2). The patient was in good condition with no signs of recurrence.

\section{Discussion and conclusion}

Germinoma, primarily arising in brachium pontis with HOD, is an enigma. Based on the brain MRI scan, the tumour involved right brachium pontis with abnormal appearance of a hypertrophic contralateral inferior olivary nucleus (ION), which may occur secondary to pontine haemorrhage, tumour, demyelination, infection, or postsurgery. In the present case, the lesion involved the dentate nucleus, the dentato-rubro-olivary component, and the main pathway of the triangle of Guilain and Mollaret, which constituted the connection between the red nucleus, ipsilateral inferior olivary nucleus, and contralateral dentate nucleus. The pathological manifestations of HOD include vacuolation and enlargement of neurons, astrocytic hyperplasia, proliferation with gliosis and demyelination [5], and hyperintensity of the olive on T2WI can appear as early as 3 to 4 weeks [6]. Only a few studies have reported on MR imaging and ${ }^{18}$ FDG-PET findings of basal ganglia GCTs. However, intracranial germ cell tumours originating from the brachium pontis 


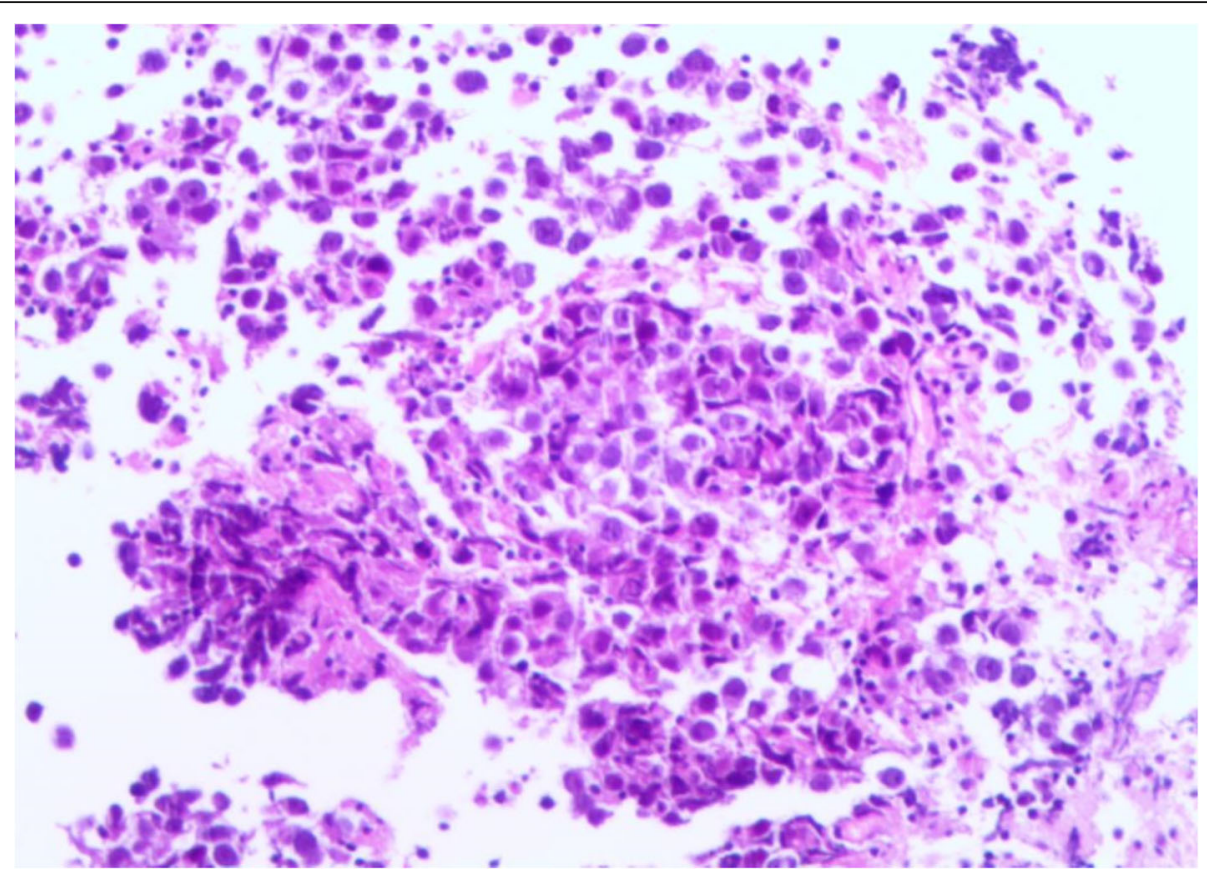

Fig. 3 Histology of the surgical specimen, indicating large cells with is that regression merely reflected shrinkage with a polygonal or spheroidal nuclei and minimal lymphocytic infiltration (Hematoxylin \& eosin stain, X400)

are the same as basal ganglia GCTs, and they all belong to atypical site GCTs. Moon WK et al. described several different MRI manifestations of germ cell tumours arising from the basal ganglia. These manifestations range from subtle nonenhancing patchy lesions to enhanced large masses [7]. On ${ }^{18}$ FDG-PET images, Vali $R$ et al. showed that the metabolism of the tumour was reduced, and the activity of the ipsilateral cerebral cortex was also decreased compared to that of the contralateral cerebral cortex [8]. Chih-Hsiang B. Yu reported a case of a fourth ventricle germ cell tumour and described the ${ }^{18} \mathrm{FDG}$ PET manifestation. The imaging results showed that the metabolic activity of ${ }^{18}$ F-FDG was significantly increased [9]. There is no evidence why germ cell tumours with the same pathology have different ${ }^{18}$ FDG-PET manifestations, and whether this difference is related to different sites, increased tumour markers and immunohistochemical types requires further study. Furthermore, because many of the nerve fibres from the dentate nucleus to inferior olive are primarily inhibitory GABArgic, damaging the dentato rural pathway results in loss of inhibitory control with consequent hyperactivity of the olivary neurons leading to abnormal involuntary movements, such as the present patient's palatal myoclonus, choreodystonia, ataxia, and dysarthria [6]

Germinomas are sensitive to radiation therapy, and patients with newly diagnosed intracranial GCTs should be considered for radiation therapy and synergism with chemotherapy to decrease the dose and volume of irradiation [10]. Whole-brain irradiation (WBI) or whole-ventricular irradiation (WVI) fields with a boost are administered at a dose from 24 to $30 \mathrm{~Gy}$, and cerebrospinal irradiation (CSI) ranged from 30 to 36 Gy with a boost to 45 to 50 Gy [11].

Primary right brachium pontis germinoma with HOD is reported for the first time. A preoperative diagnosis is challenging on account of the absence of representative clinical and neuroimaging characteristics. In contrast, the patient could have favourable prognoses with appropriate evaluation and therapy.

\section{Abbreviations}

HOD: Hypertrophic olivary degeneration; MRI: Magnetic resonance imaging; T2WI: T2-weighted images; FLAIR: Fluid-attenuated-inversion-recovery; Gd: Gadolinium; ION: Inferior olive nucleus; LGG: Low-grade glioma;

GCTs: Germ cell tumours; T1WI: T1 weighted image; AFP: Alpha-fetoprotein; IHC: Immunohistochemistry; ${ }^{18}$ F-FDG PET/CT: ${ }^{18}$ F-fluorodeoxyglucose positron emission tomography/computed tomography; SUVmax: Maximum standardized uptake value; WBI: Whole-brain irradiation; WVI: Wholeventricular irradiation; CSI: Cerebrospinal irradiation

\section{Supplementary Information}

The online version contains supplementary material available at https://doi. org/10.1186/s12883-021-02238-0.

Additional file 1: Figure S1. The follow-up MRI (16 months later). Axial T2WI (A) and FLAIR (B) MRI demonstrate that the lesion in the right brachium pontis disappeared. Axial T2WI (C) and FLAIR (D) demonstrate that the hypertrophic left ION disappeared.

Additional file 2: Figure S2. Axial T1WI (a) and T2WI (b) MR images revealed $\mathrm{HOD}$ after chemoradiotherapy (red arrow). 


\section{Acknowledgements}

The authors thank the patient for his contributions and my roommates, especially

Yi Yang, for putting up with my noise during writing of the manuscript.

\section{Authors' contributions}

Writing - original draft preparation: YL \& PW; Writing - review and revise: JF \& JW

design of the work: XQ \& JZ. All authors have approved the submitted version.

\section{Funding}

This work was supported by the Beijing Municipal Bureau of Health (to

Xiaoguang Qiu, Grant number: N/A).

\section{Availability of data and materials}

Not applicable.

\section{Declarations}

Ethics approval and consent to participate

Not applicable.

\section{Consent for publication}

We obtained the patient's written consent to publish his or her personal or clinical data and any identifying images in this study.

\section{Competing interests}

The authors declare that they have no competing interests.

Received: 25 November 2020 Accepted: 14 May 2021

Published online: 25 May 2021

\section{References}

1. Thakkar JP, Chew L, Villano JL. Primary CNS germ cell tumors: current epidemiology and update on treatment. Med Oncol. 2013;30(2):496. https:// doi.org/10.1007/s12032-013-0496-9.

2. Nakase H, Ohnishi H, Touho H, Karasawa J, Tsunoda S. Cerebellar primary germ-cell tumor in a young boy. Brain Dev. 1994;16(5):396-8. https://doi. org/10.1016/0387-7604(94)90128-7.

3. Masuzawa T, Shimabukuro H, Nakahara N, Iwasa H, Sato F. Germ cell tumors (germinoma and yolk sac tumor) in unusual sites in the brain. Clin Neuropathol. 1986;5(5):190-202.

4. Hao S, Li D, Feng J, Wang L, Wu Z, Zhang J, et al. Primary medulla oblongata germinomas: two case reports and review of the literature. World J Surg Oncol. 2013;11:274. https://doi.org/10.1186/1477-781 9-11-274.

5. Horoupian DS, Wisniewski H. Neurofilamentous hyperplasia in inferior olivary hypertrophy. J Neuropathol Exp Neurol. 1971;30(4):571-82. https:// doi.org/10.1097/00005072-197110000-00002

6. Akar S, Drappatz J, Hsu L, Blinder RA, Black PM, Kesari S. Hypertrophic olivary degeneration after resection of a cerebellar tumor. J Neuro-Oncol. 2008; 87(3):341-5. https://doi.org/10.1007/s11060-008-9523-7.

7. Moon WK, Chang KH, Kim IO, Han MH, Choi CG, Suh DC, et al. Germinomas of the basal ganglia and thalamus: MR findings and a comparison between MR and CT. AJR Am J Roentgenol. 1994;162(6):1413-7. https://doi.org/1 0.2214/ajr.162.6.8192009.

8. Vali R, Khazaee A, Widjaja E, Bouffet E. The potential role of 18F-FDG PET in the early detection of Basal Ganglia Germinoma in a 13-year old patient with diabetes insipidus. Ann Clin Case Rep. 2016:1:1052.

9. Yu CH, Peller PJ, Subramaniam R. F-18 FDG PET/CT imaging of intraventricular germinoma. Clin Nucl Med. 2009;34(6):393-4. https://doi. org/10.1097/RLU.0b013e3181a34540.

10. da Silva NS, Cappellano AM, Diez B, Cavalheiro S, Gardner S, Wisoff J, et al. Primary chemotherapy for intracranial germ cell tumors: results of the third international CNS germ cell tumor study. Pediatr Blood Cancer. 2010;54(3): 377-83. https://doi.org/10.1002/pbc.22381.

11. Dattoli MJ, Newall J. Radiation therapy for intracranial germinoma: the case for limited volume treatment. Int J Radiat Oncol Biol Phys. 1990;19(2):42933. https://doi.org/10.1016/0360-3016(90)90553-v.

\section{Publisher's Note}

Springer Nature remains neutral with regard to jurisdictional claims in published maps and institutional affiliations.

Ready to submit your research? Choose BMC and benefit from:

- fast, convenient online submission

- thorough peer review by experienced researchers in your field

- rapid publication on acceptance

- support for research data, including large and complex data types

- gold Open Access which fosters wider collaboration and increased citations - maximum visibility for your research: over $100 \mathrm{M}$ website views per year

At $\mathrm{BMC}$, research is always in progress.

Learn more biomedcentral.com/submissions 